\title{
Mediators of Development of Brand Personality in Iran Football League
}

\author{
1Fakhrossadat Tabatabaeian ${ }^{*},{ }^{2}$ Mohammad Khabiri, ${ }^{1}$ Mehdi Rasooli
}

${ }^{1}$ Sport Management Department, Sport Sciences Research Institute of Iran, Tehran, Iran. ${ }^{2}$ Sport Management Department, Faculty of Sport Sciences, University of Tehran, Tehran, Iran.

\begin{abstract}
Background. Brand personality as a part of brand identity plays an important role in communications; if a brand has no personality, it cannot introduce itself and stay in the mind of the customer. Customer understanding about a brand is far more important than what is expressed as brand reality. Thus, developing an appropriate personality for creating a compatible image of the brand in the customer's mind will be an important factor. Therefore, organizations must develop appropriate primitive principles to establish a long relationship with customers. Objective. This study was conducted to identify and introduce intervening and fundamental factors affecting the formation of brand personality of the Iran Football league. Methods. Here, a qualitative research was conducted using a grounded research method. Data collection tools involved deep interviews with experts (23 individuals) selected by purposive and snowball sampling. Data analysis was performed using open encodings, axial, and selective methods. Results. Based on the qualitative interviews, 33 signs were obtained for conditions influencing the formation of league brand personality (contextual factors and intervening conditions). Having analyzed these factors and summarized the findings based on the connection index and similarity with each other, and with the constant comparison, these signs were eventually reduced to five concepts or categories including product factors, factors unrelated to the product as well as the external and macro environment. Conclusion. If brand personality is defined based on market research or people's tastes, adapting the whole system with the brand personality and present promises is a tedious task. On the other hand, the research method contributes to obtaining the same pattern for each product category or service. So in order to build a brand personality from the organization perspective, managers and planners should identify intervening conditions and contextual factors which can disrupt the strategies adopted (intervening factors). Alternatively, with appropriate contextualization, they can contribute to the development of these strategies and act toward these factors for the formation of the brand personality of the league.
\end{abstract}

KEY WORDS: Football, Brand Personality, Congruency, Football, Product Factors, Unrelated Factors with Product, External Environment.

\section{INTRODUCTION}

For researchers of management field, brand personality is an ordinary and well-known subject. For the first time, Aaker introduced the brand personality, a subject arising from the fields of psychology and sociology, to the marketing field.
Aaker scientifically put forward the human look to the brand and believed that brand personality has a series of human features (1). He introduced the animism theory in welcoming consumers from the description of inhuman objects in brand personality

*. Corresponding Author:

Fakhrossadat Tabatabaeian

E-mail: tabatabaeian2009@yahoo.ca 
of clothing and five-dimensional model (the dimensions include: sincerity, competence, excitement, ruggedness, and sophistication) designed for brand personality. Despite criticism of her model, in this way she could significantly contribute to development of further research. She stated that brands with the definition of human personality from themselves give promise to consumers where these personality features are shaped by the activities of the organization, such as the image in the minds of consumers, becoming the basis for communications of brand with consumers (2). If the character developed in the mind of the customer is not based on the goals of the organization or is considerably different from it, it will not help increase the brand power of the organization. Brand personality influences consumers' preferences and attitudes and contributes to development of emotional bonds, trust, and loyalty in the consumer (3). All these are crucial factors that sports organizations need to achieve (4).

\section{Brand personality approach and sport}

Customers often try to establish the association of ideas between the benefit that a product or service brings for them and personal value. In other words, customers buy goods or services, but they are basically looking for their benefits. These benefits can be instrumental or can involve psychosocial benefits related to the perception of customers from themselves and what they like others think about them. This impression, which is formed based on brand personality, is very important and vital (5). Most research in the field of consumer behavior on self-congruity has proved that self-congruity has a relationship with consumer behavior (6). Similarly, sports fans are also attracted to their favorite teams for relating their personality to their features. For example, fans of the NBA (The National Basketball Association) athletic club (the largest professional men's basketball league in North America) are fond of the San Antonio Spurs Basketball Team, since they want to have a successful (qualified) and healthy team (honesty) (7). This self-congruity can occur in three aspects for the individual: one is selfcongruity between the real self-concept of the person and brand personality which leads to satisfaction of the need to stability and strength of the individual. The second is ideal self-concept with self-congruity incorporated in it, where brand personality leads to the individual's satisfaction with their self-confidence. Finally, the third is the idea of social ideal self-concept where selfcongruity causes customer satisfaction with their social approval (6). The concept of brand personality is well known subject in areas related to professional athletic clubs which can help teams increase supporters and attract sponsors (6). Nevertheless, this subjects still suffers from a research gap (8-10). Studies have shown that researchers of this field have been working to test the brand personality model, define scaling for it, examine the direct and indirect effects of the brand personality, the dynamics of its dimensions, and the use of brand personality in related fields. Some have also investigated its role in brand development (11). Meanwhile, the Iran Football league has weaknesses in most of these research areas (12). In this regard, we can refer to the studies of Shafaie et al., Asadollahi et al., and Tabatabaeian, Khabiri, and Rasouli $(9,12,13)$. The results of exploratory and factor analysis of Shafaie et al. research from the viewpoint of the fans indicated that the dimensions of brand personality of the top league football teams form seven unique dimensions including perfection, stunning, distinctive, exciting, classic and successful (9). Asadollahi et al. also referred to seven factors in assessing the factors affecting sport's brand personality of Iran clubs. These factors were symbolism, loyalty, originality, attractiveness, validity, excitement, emotions, where attractiveness, contrary to the "emotional" factor, is one of the most important factors (13). Indeed, these few studies which have been conducted so far have only determined or evaluated brand personality traits expressed only based on crosssectional feelings of fans. Here, there may be mismatch between the image of the league and the perceptions of the fans. This formation must be realized by a systemic and guided process to pursue the major goals of Football league. Tabatabaeian, Khabiri, and Rasouli studied the strategies and outcomes of the formation process of the character of the Premier League, and the present study can be considered as a supplementary research for it (13).

Aware and compassionate managers and planners know that if character recognition of brand is defined based on market research or people's tastes, adapting the whole system with 
the brand personality and preset promises is tedious task. Indeed, many times, the organization cannot tolerate all these changes and current customers may face a dichotomy of identity about the league. On the other hand, research methods contribute to obtaining the same pattern for each category of product or league service. Therefore, it can show which activity is essential for shaping brand personality from the perspective of the strategic organization. Then, according to that the position of this character is also captured in the organization's statement; identification of intervening factors that lead to strategy deviations and identification of contextual factors which are fundamental to performing strategies, which is considered crucial.

Accordingly, the present study is the first research conducted fundamentally and profoundly to identify the factors contributing to the formation of "brand personality in the field of sport (Iran Football league) and the intervening factors in its formation.

\section{MATERIALS AND METHODS}

Participants. The participants of the study consisted of 23 experienced and informed experts including: faculty members in the fields of sports management, sport sociology, sport psychology, as well as football experts, managers, and executive specialists with experience in the upper and middle levels of the football league organization, Premier League football clubs, Federation and Football Union, experts of branding, and active sport media (Table 1).
Research tool. Deep and semi-structured interviews constituted the research instrument.

Data collection. For sampling to conduct interviews, purposive and snowball samplings were used, and the sampling continued until the research team concluded that the new information is a replication of the previous information and no new information is obtained. Finally, after conducting the 23 interviews, the research reached the theoretical and adequacy saturation. Theoretical saturation refers to the stage where no new data related to the category is created (10). The interviews were conducted individually, with each implemented before the next interview. Then, according to the findings obtained from it, the next interview was performed. Since in the grounded study, the analysis begins quickly, and the early stages of the study have an exploratory nature, research literature was not used to prevent guiding the data gathering process. Accordingly, three sampling steps were used to collect data at each stage of the grounded theory; free sampling was used to collect sufficient data to start the code with purposive - snowball sampling where these three stages are open-ended and "relational" sampling, in order to use the primary code as the basis for gathering more contents. Then, in the last step of this research, a systematic approach in data collection was used to help develop the main category. According to Corbin (1991), it was performed in three steps of open coding, axial, and selective stages. To ensure the validity of the research, measures were taken such as comparison by the members, peer review, and collaborative research.

Table 1. Research participants (interviewees)

\begin{tabular}{ll}
\hline Faculty Members & 8 individuals \\
Managers and executive authorities of the organizations and clubs & 8 individuals \\
Sports media & 3 individuals \\
experts in the brand field & 4 individuals \\
\hline
\end{tabular}

\section{RESULTS}

According to the findings, the factors were analyzed in three stages: coding, identification, and summarization. Based on the qualitative interviews, 33 signs were obtained for the conditions (contextual factors and intervening conditions) affecting the formation of brand personality league. Having analyzed these factors and summarized the findings based on the connection index and similarity with each other and constant comparison, these signs were eventually reduced to five concepts or categories (Figure 1).

"External/macro environment"; known with sub-components of football is under government supervision, legal requirements, media, and economic factors, as intervening conditions. In this regard, we can state that today, governmental sports organizations in terms of 
operational efficiency and financial performance are below than the optimal level and are not favored by the general public. Indirect competition of the government with the private sector, managers' resistance to convert the enterprise due to their dependence on the public sector, lack of investment security in the country, and the state's use of sport as a political tool are the most important management, cultural, social, economic, legal, and political barriers ahead of privatization of sports in the country.

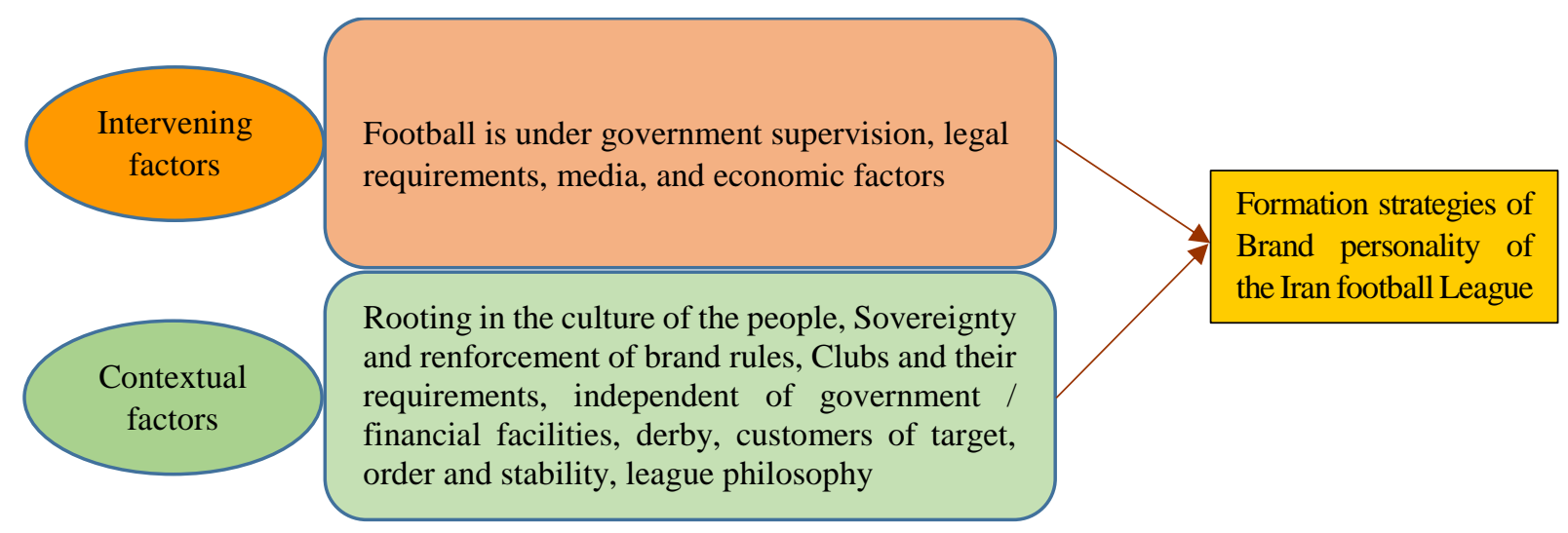

Figure 1. Factors Affecting the ways of formation of brand personality League.

The interviewee expressed his opinion on these issues:

Mr. $\boldsymbol{R}$. Kh: Our league organization, in terms of the economic cycle is not stable and when anyone wants to be sponsor, there is no guarantee for it. The main reason is that they are not private.

Concerning formation of the character of the league and emergence of its brand personality, several factors were also counted, including football culture, the rule of the brand, the philosophy of the league, clubs, and their requirements, independent of the state, derby, order and stability, and target groups. In this way, when the culture of professional football is accepted in the society and coordinated with the culture of the people of society, there will be no contradictions. In response, it will be embraced by the people and its character will be shaped based on common people's beliefs (11).

The interviewee stated his opinion about this matter:

Mr A.CH: If a team does not have deep roots and old culture, it will not form a team with money; in a city, the people's customs, cultural issues, historical backgrounds and other factors have to help each other to form a team.

As mentioned previously, the existence of strong and clear rules,"not bureaucratic and ineffective rules" was another obtained factor. In this regard, one can refer to the most important legal barriers to brand creation, lack of compliance with copyright law in the country, lack of mandatory rules for the professionalization of clubs, lack of a television broadcasting law, absence of laws protecting the brand, and lack of systemic laws for open economy. The presence of high-identity clubs in league competitions, the role of derby games and strengthening city teams, order and stability in all things and at all levels of activity (managers, quality of service, holding competitions, selling tickets of the tournaments, contracts signed with sponsors) ... have been other identified factors of brand personality of the football league.

The interviewee expressed his idea about these issues:

Mr. R. M: People know the identity of city's team for themselves; Identity of their province; identity of their city. I'll give an example, Tractor Sazi Tabriz. The day that the league competition was held, all the people of the city had come 
because they were mostly looking for the identity of their city.

Furthermore, "customers and target groups" was another sign identified in the fundamental factors for brand personality of the Premier League. The league manager should pay a special attention to the pioneering customers as well as target customers in order to be able to reveal the league brand with attractive personality and consistent with the consumer themselves. The philosophy of the league was another identified factor which must be cared for in the management of the organizational brand and at the macro level of the league.

\section{DISCUSSION}

Today, governmental sports organizations in terms of operational efficiency and financial performance are below than the optimal level and are not favored by the general public. Therefore, many sports organizations which are entirely owned by the government and managed in a state form are facing shortage of budget. This situation has resulted in the removal or reduction of services and organized events by these organizations. Possibly, the main cause of Iran's sport problems is that Iran's economy is governmental and acts as introvert and monopolist, which has also caused Iran's sports industry to face difficulty. As long as the government helps the clubs, they also have no interest in investing directly in the sports industry, and this is the reason why a large number of supporters have been lost. The findings of Aghaei, Oboudi, and Zare showed the necessity of economic and financial conditions as one of the requirements to avoid failure of football clubs in Asian competitions (14). Seyed Bagheri and Sharifian also considered government laws as one of the biggest factors behind the lack of sponsor support for championship sport (15).

Instability in monetary and financial policies of the country, non-participation of foreign investors in internal capital markets, governmental ownership of many industries, factories, institutions and sports and non-sports organizations, lack of economic security, and the high risk of investing in football professional sport, have also created an inappropriate context for the private sector investing in professional football.

Constant and unceasing changes in the macroeconomic variables of the country, inappropriate tax laws for investing in professional football clubs of the country, inappropriate allocation of television broadcasting rights, and advertising around the football field can be added as economic factors. On the other hand, the brands of clubs and leagues possessing a long history which are rooted in people's culture will have a greater potential for finding character. Clubs can provide the necessary factors to grow their brand personality by having well-known players and coaches, attractive and homely stadiums, continuous successes, previous successful history, famous sponsors, traditions and values, team performance, club management, fans and their team identity, the club's geographical brand, flag, logo, and name, and even the colors used in it.

Existence of strong and clear rules,"not bureaucratic and ineffective rules" was another obtained factor. In other words, it refers to laws which are facilitators and protectors, not inhibitor and ineffective. From the most important legal barriers of brand building, one can mention lack of compliance with copyright law in the country, lack of mandatory rules for the professionalization of clubs, lack of a television broadcasting law, absence of laws protecting the brand, and lack of systemic laws for open economy. The results of the research of HematiNejad and Goharrostami, and Hosseini and Seyed Bagheri and Sharifian also support these findings $(15,16)$.

Media also through converting football values contribute to its acceptance as a value. Indeed, they have played a significant role in strengthening and creating a sense of loyalty to sport teams.

Identification with teams through the sports mass media have led to the identification of these teams and will cause the fans to consider sport's club as a part of their own, such that they will be happy with its success and sad with its failure. Zare, Heydari Nejad and Shirali, and Gill, and Andrews have confirmed the role of the media in their findings (17-19) (Table 2). 
The roles of derby games and strengthening city teams, order and stability in all things and all levels of activity (managers, quality of service, holding competitions, selling tickets of the tournaments, contracts signed with sponsors) (20) were identified as fundamental factors of brand personality of the football league. The findings of other studies also confirm this point (21). According to their explanation, it can be said that the more top quality football matches are thanks to the presence of successful and famous club teams, the larger the number of people who want to watch those matches will be. Derby matches in all countries have great attraction for fans of both teams, like Aston Villa and Birmingham, Newcastle and Sunderland, and Everton versus Liverpool, and independence versus victory. City teams have also a great deal of public support since the people know these teams as a symbol of their pride and social identity, and support them as supporters of their area and their reputation, become upset with their defeat failure and become joyful with their victory. They consider supporting these teams as equal to supporting their region and city and support it in dignity and consider any failure or victory of these teams as failure or victory of themselves. In terms of content, the findings of Javani et al. can also be the evidence to this claim (22). "The quality of the result" has the greatest effect on the satisfaction of the spectators (23) and as the football match grows in quality and cause pride in spectators, then more people will want to watch it $(20,24)$. Further, in addition to spectator's satisfaction, it will also have benefits like increasing television broadcasting fees, increasing advertising around the field and on shirts and sport clothes, as well as the attraction of sponsors. Definitely, this depends on the status of the clubs, where the status of clubs in a country has a more favorable level and are closer to professional standards, and national championships (leagues) will be at high level and quality. Also, the pioneers and customers of the brand's goal can also influence its personality. The findings of Silva and Casas and the findings of Niedrich and Swain can confirm this matter $(25,26)$. The philosophy of the league was also an identified factor for league personality preparation. The philosophy of the league, which is seen in the macro management organization, should determine great goals for positioning, philosophy, and league brand strategies and these goals should be implemented in the organizational culture of the league (Table 3 ).

Table 2. Intervening Factors

\begin{tabular}{|c|c|c|c|}
\hline Concept & Subcategory & Sign & $\begin{array}{c}\text { corroborated } \\
\text { researches }\end{array}$ \\
\hline \multirow{4}{*}{$\begin{array}{c}\text { Outside } \\
\text { Environment / } \\
\text { Macro }\end{array}$} & $\begin{array}{l}\text { Governmental } \\
\text { Being of } \\
\text { Football }\end{array}$ & $\begin{array}{l}\text { governmental being of football, Political } \\
\text { interferences (political individuals interested in } \\
\text { football and clubs), impregnated to security space } \\
\text { and detective events, Removing of women from } \\
\text { stadiums, Political factors }\end{array}$ & $\begin{array}{c}\text { Hemati-Nejad, } \\
\text { Goharrostami, and } \\
\text { Hosseini (2017) (16) }\end{array}$ \\
\hline & Media & Media & $\begin{array}{l}\text { Slak Valek (2018) } \\
\text { (27) } \\
\text { Gill (2018) (18) }\end{array}$ \\
\hline & Rules & $\begin{array}{l}\text { Rules (cumbersome rules and ineffective rules), } \\
\text { brand rules }\end{array}$ & $\begin{array}{l}\text { Seyed Bagheri, and } \\
\text { Sharifian (2018) (15) } \\
\text { Hemati-Nejad, } \\
\text { Goharrostami, and } \\
\text { Hosseini (2017) (16) }\end{array}$ \\
\hline & Economic factors & $\begin{array}{l}\text { Economic factors (economic stability, Income } \\
\text { generation, the strength and power of other social } \\
\text { institutions ...) }\end{array}$ & Quyet (2017) (28) \\
\hline
\end{tabular}

This philosophy, in the case of the brand, will be the presenter of organization image which can shape the minds of customers. Hunk Shale findings can also confirm this finding (8). 
Table 3. Contextual Factors

\begin{tabular}{|c|c|c|c|}
\hline Concept & Subcategory & Sign & $\begin{array}{l}\text { Corroborated } \\
\text { researches }\end{array}$ \\
\hline \multirow{8}{*}{$\begin{array}{l}\text { Unrelated } \\
\text { Factors } \\
\text { with } \\
\text { Product }\end{array}$} & $\begin{array}{l}\text { rooted in people's } \\
\text { culture and in line } \\
\quad \text { with it }\end{array}$ & $\begin{array}{l}\text { acceptation of professional football culture rooted in } \\
\text { the culture of the people and in line with it in society } \\
\text { must have rooted in the culture of people and be based } \\
\text { on common people's beliefs }\end{array}$ & $\begin{array}{l}\text { Gayo and Rowe } \\
\text { (2018) (29) }\end{array}$ \\
\hline & $\begin{array}{l}\text { sovereignty of brand } \\
\text { laws and their } \\
\text { implementation }\end{array}$ & $\begin{array}{l}\text { Sovereignty and formalization of brand rules, } \\
\text { awareness and understanding brand knowledge with } \\
\text { human resources (managers, employees, etc.) ..., } \\
\text { existence of supporter rules }\end{array}$ & $\begin{array}{l}\text { Javani et al., } \\
(2016)(22)\end{array}$ \\
\hline & $\begin{array}{l}\text { philosophy of the } \\
\text { league }\end{array}$ & & $\begin{array}{l}\text { Schilhaneck } \\
(2008)(8)\end{array}$ \\
\hline & $\begin{array}{l}\text { clubs and its } \\
\text { requirements }\end{array}$ & $\begin{array}{l}\text { Existence of well-known and powerful clubs (star } \\
\text { players, famous coaches, famous stadium, continuous } \\
\text { successes, possess of famous names and elements, } \\
\text { club's age, club's traditions, geographical brand of the } \\
\text { club, connoisseur owners and managers and believe in } \\
\text { the brand, history and honors of the club, culture and } \\
\text { values of the club, club supporters, club management, } \\
\text { team performance, fans, team identity, fan identity }\end{array}$ & $\begin{array}{l}\text { Rasooli et al. } \\
(2016) \&(2013) \\
(30,31)\end{array}$ \\
\hline & $\begin{array}{l}\text { independent of the } \\
\text { government / keeping } \\
\text { of independence } \\
\text { (financial resources) }\end{array}$ & $\begin{array}{l}\text { support by government but independent financial } \\
\text { facilities of it }\end{array}$ & $\begin{array}{l}\text { Moshabbeki } \\
\text { Esfahani et al. } \\
\text { (2014) (32) }\end{array}$ \\
\hline & derby & $\begin{array}{l}\text { Being high the level and quality of the derby league, } \\
\text { strengthen of city teams }\end{array}$ & \\
\hline & order and stability & $\begin{array}{l}\text { stability (financial, managers, rules, standards, quality } \\
\text { of customer service, ... ) }\end{array}$ & $\begin{array}{c}\text { Seifpanahi } \\
\text { Shabani and Haji } \\
\text { Hasani (2017) (21) }\end{array}$ \\
\hline & $\begin{array}{l}\text { customers/ target } \\
\text { groups }\end{array}$ & $\begin{array}{l}\text { Fans and their identity, supporters and their identity, } \\
\text { licensors, media, loyal fans }\end{array}$ & $\begin{array}{c}\text { da Silva and } \\
\text { Luzzi (2017) (25) }\end{array}$ \\
\hline
\end{tabular}

From the viewpoint of the researcher, trace of obtained findings or their effect can be seen in many other phenomena in the national football league. Therefore, managers and planners of the league, paying attention to the obtained finding, can take appropriate strategies and make decisions ahead of them and present a good image of the league for fans and beneficiaries. This, in turn, contributes to synergy and alignment with other management activities of the league organization.

\section{CONCLUSION}

In this regard, the present research is the first study that has tried to identify intervening and contextual factors in achieving the personality, league, managers and planners, but had also some limitations. The collected data was from the perspective of male experts and the views of managers and experts of female in the football field were not included. Also, this research only analyzed the opinions of experts, and the viewpoint of fans and consumers should also be taken into account in order to determine the extent of alignment of league organization with customers and consumers (product and service of the league).

\section{APPLICABLE REMARKS}

- To achieve brand personality of the football league from the perspective of the organization, identified factors; can determine axis of planning of managers and league strategic planners to achieve this.

- To shape the minds of the football league customers in line with the macro goals of league, determination of the brand personality of the league could be effective. 


\section{REFERENCES}

1. Aaker D. Aaker on Branding: 20 Principles That Drive Success. 1st ed: Morgan James Publishing 2014. 220 p.

2. Aaker JL. Dimensions of brand personality. Journal of Marketing Research. 1997;34:347-56.

3. Echevarria RM. A Content Analysis of NFL Team Online Branding. Elon Journal of Undergraduate Research in Communications. 2017;8(2):96-104.

4. Stadler Blank A, Koenigstorfer J, Baumgartner H. Sport team personality: It's not all about winning! Sport Management Review. 2018;21(2):114-32.

5. Keller KL. Brand Planning 1st ed: Shoulders of Giants 2008. 64 p.

6. Schade M, Piehler R, Burmann C. Sport club brand personality scale (SCBPS): A new brand personality scale for sport clubs. Journal of Brand Management. 2014;21(7):650-63.

7. Carlson BD, Donavan DT. Human Brands in Sport: Athlete Brand Personality and Identification. Journal of Sport Management. 2013;27(3):193-206.

8. Schilhaneck M. Brand management in the professional sports club setting. European Journal for Sport and Society. 2008;5(1):43-62.

9. Shafaie L, Memari Z, Asghari Jafarabadi M. The Brand Personality of Selected Iranian Football League Teams: Explaining Dimensions and Modeling. Sport Management and Development. 2016;5(1):117-36 [Article in Farsi].

10. Strauss A, Corbin J. Grounded Theory Methodology: An Overview. In: NDenzin oK, Lincoln YS, editors. Strategies of Qualitative Inquiry. Thousand Oaks, Calif: Sage Publications; 1998 p. 158-83.

11. Radler VM. 20 Years of brand personality: a bibliometric review and research agenda. Journal of Brand Management. 2018; 25(4):370-83.

12. Tabatabaeian F, Khabiri M, Rasouli M. Brand Personality of the Premier League of Iran's Soccer-Strategies and Consequences. Annals of Applied Sport Science. 2018;6(2):87-94.

13. Asadollahi A, Heidarzadeh Hanzaee K, Abdolvand M, Reshadatjooh H. Developing a Scale Sport Brand Personality in Iranian Sport Teams. Research Journal of Recent Sciences. 2015;4(11):83-7.

14. Aghaei N, Oboudi A, Zare F. The reasons of Iranian football clubs failure in the Asian football champion's league. European Journal of Sports and Exercise Science. 2014;3(4):11-8.

15. Seyed Bagheri SM, Sharifian E. Identifying and prioritizing barriers to sponsorship of private companies of sport of champions. Journal of Sport Management and Motor Behavior. 2017;7(13):55-66 [Article in Farsi].

16. Hemati-Nejad M, Goharrostami H-R, Hosseini SS. Requirements for Privatization of Iran Pro League Football Clubs Physical Education of Students. 2017;21(1):33-9.

17. Andrews DL. Sport and the Transnationalizing Media Corporation. Journal of Media Economics. 2009;16(4):235-51.

18. Gill R. The Influence of Media Platforms on Sport Reputation: An Australian Football League Case Study. Journal of Sports Media. 2018;13(1):123-51.

19. Zare A, Heydari Nejad S, Shirali R. The Impact of Mass Media on the Control of Corruption in Football. Communication Management in Sports Media. 2016;3(12):13-26 [Article in Farsi].

20. Berendt J, Uhrich S. Enemies with benefits: the dual role of rivalry in shaping sports fans' identity. European Sport Management Quarterly. 2016;16(5):613-34.

21. Seifpanahi Shabani J, Haji Hasani M. The Effective Factors in Promoting of Iranian Sport National Teams. Annals of Applied Sport Science. 2017;5(4):77-84.

22. Javani V, Ehsani M, Amiri M, Kozechian H. Sport Branding Model by Strategic Thinking approach in Iran. Contemporary Studies on Sport Management. $r \cdot 1 \vee ; 6(1)$ ):43-56 [Article in Farsi].

23. Emadi M, Nasseh M. Analysis of affecting factors on fans' satisfaction and attendance in Iran football Premier League's stadium. Sport Management and Development. 2014;3(2):63-75 [Article in Farsi].

24. Eddosary M, Ko YJ, Sagas M, Kim HY. Consumers' Intention to Attend Soccer Events: Application and Extension of the Theory of Planned Behavior. Psychological Reports. 2015;117(1):89-102.

25. da Silva ECLC, Luzzi A. Sport fans as consumers: An approach to sport marketing. British Journal of Marketing Studies. 2017;5(4):36-48.

26. Niedrich RW, Swain SD. The Influence of Pioneer Status and Experience Order on Consumer Brand Preference: A Mediated-Effects Model. Journal of the Academy of Marketing Science. 2003;31(4):468-80.

27. Slak Valek N. The relationship between community sporting event participants and the media. The case of Abu Dhabi. Journal of Sport \& Tourism. 2018;22(3):187-205.

28. Quyet HM. To examine the issues which national sports federations/associations in Vietnam are encountering and potential solutions. Seoul, South Korea: Seoul National University; 2017 [Abstract in English].

29. Gayo M, Rowe D. The Australian sport field: moving and watching. Media International Australia. 2018;167(1):162-80. 
30. Rasooli M, Khabiri M, Elahi A, Aghaee N. Internal factors and obstacles of brand management in Iran's pro league football clubs. Sport Management Studies. 2016;8(35):51-66 [Article in Farsi].

31. Rasouli SM, Saatchian V, Elahi A. Distribution Of Competitive Balance In Iran Football Pro League And Europe Pro League With Economically Indexes (K Top Team, Lorenz Curve And Gini Coefficient). Sport Management Review. 2013;10(17):175-90 [Article in Farsi].

32. Moshabbeki Esfahani A, Vahdati H, Khodadad Hosseini SH, Ehsani M. Designing The Brand Identity Model of Iranian Sports Industry (Case Study: Football Premier League). Management Research in Iran. 2014;17(4):203-23 [Article in Farsi]. 